\title{
A MODERNIDADE PEDAGÓGICA NAS REPÚBLICAS DO RIO DA PRATA: O OLHAR DO VIAJANTE NESTOR DOS SANTOS LIMA (1923)
}

\author{
Laís Paula de Medeiros Campos Azevedo* \\ Olívia Morais de Medeiros Neta**
}

\section{RESUMO}

O nosso estudo se dedica à análise das representações de Nestor dos Santos Lima sobre a organização escolar nas Repúblicas do Rio da Prata a partir de sua viagem pedagógica, realizada no ano de 1923, às cidades de Buenos Aires e Montevidéu. O intelectual norte-rio-grandense Nestor dos Santos Lima se destacou no cenário estadual e nacional pela sua atuação enquanto educador, advogado e historiador, e pela sua participação nas diferentes e mais relevantes instituições educacionais e culturais do Estado durante a primeira metade do século XX. Nosso referencial teórico é composto pelas contribuições de Roger Chartier, Michel de Certeau e Jean François Sirinelli. O corpus documental para a pesquisa se constitui, principalmente, pelo relatório da viagem produzido pelo intelectual. A partir do olhar do viajante, foi possível identificar os principais elementos que caracterizavam a organização do ensino, sobretudo

\footnotetext{
* Universidade Federal do Rio Grande do Norte (UFRN), Natal/RN, Brasil.

${ }^{* *}$ Universidade Federal do Rio Grande do Norte (UFRN), Natal/RN, Brasil.
} 
primário e normal, nas cidades visitadas.

Palavras-chave: história da educação, modernidade pedagógica, viagens pedagógicas, Nestor Lima.

\title{
MODERNIDAD PEDAGÓGICA EN LA REPÚBLICA DEL RÍO DE LA PLATA: LA VISTA DEL VIAJERO NESTOR DOS SANTOS LIMA (1923)
}

\section{RESUMEN}

Nuestro estudio se dedica al análisis de las representaciones de Néstor dos Santos Lima sobre la organización escolar en las Repúblicas del Río de la Plata a partir de su viaje pedagógico en 1923 a las ciudades de Buenos Aires y Montevideo. El intelectual Néstor dos Santos Lima se destacó en la escena estatal y nacional por su labor como educador, abogado e historiador, y por su participación en las diferentes y más relevantes instituciones educativas y culturales del Estado durante la primera mitad del siglo XX. Nuestra referencia teórica está compuesta por las contribuciones de Roger Chartier, Michel de Certeau y Jean François Sirinelli. El corpus documental para la investigación está constituido principalmente por el informe de viaje producido por el intelectual. Desde la perspectiva del viajero, fue posible identificar los principales elementos que caracterizaron la organización de la educación, especialmente la primaria y la normal, en las ciudades visitadas.

Palabras clave: historia de la educación, modernidad pedagógica, viajes pedagógicos, Néstor Lima.

\section{PEDAGOGICAL MODERNITY IN THE REPUBLIC OF RIO DA PRATA: THE VIEW OF THE TRAVELER NESTOR DOS SANTOS LIMA (1923)}

\begin{abstract}
Our study is dedicated to the analysis of the representations of Nestor dos Santos Lima on the school organization in the Republics of Rio da Prata from his pedagogical trip, carried out in 1923, to the cities of Buenos Aires and Montevideo. The intellectual Nestor dos Santos Lima stood out on the state and national scene for his role as an educator, lawyer and historian, and for his participation in the different and most relevant educational and cultural institutions of the State during the first half of the 2oth century. Our theoretical framework is composed by the contributions of Roger Chartier, Michel de Certeau and Jean François Sirinelli. The documentary corpus for there search is constituted mainly by the trip report produced by the intellectual. From the perspective of the traveler, it was possible to identify the main elements that characterized the organization of education, especially primary and normal, in the cities visited.
\end{abstract}

Keywords: history of education, pedagogical modernity, pedagogical travel, Nestor Lima. 


\section{LA MODERNITÉ PÉDAGOGIQUE EN RÉPUBLIQUE DU RIO DA PRATA: LA VUE DU VOYAGEUR NESTOR DOS SANTOS LIMA (1923)}

\section{RESUME}

Notre étude est dédié à l'analyse des represéntations de Nestor dos Santos Lima sur l'organisation scolaire dans les republiques du riviére de l'argent À partir de son Voyage pédagogique, réalisée em 1923 dans les villes de Buenos Aires et Montevideo. L'intellectuel du Rio Grande do Norte, Nestor dos Santos Lima s'est distingue sur la scénaire d'etat et nacionale par son action comme éducateur, avocat et historien, et pour sa participation aux différents instituitions éducatives et culturelles, le plus pertinentes de l'État au cours de la première milieu du siécle XX. Notre référentiel théorique est composé des contribuitions de Roger Chartier, Michel de Certeau et Jean François Sirinelli. Le corpus documentaire de la recherche est constitué principalement par ler apport de Voyage produit par l'intelectuel. Du point de vue du voyageur, il été possible identifier les principaux éléments qui ont caractérisé l'organisation de l'éducation, em particulier l'enseignement primare, secondaire et normal dans les villes visitées.

Mots-clés: histoire de l'éducation, modernité pédagogique, voyages pédagogiques, Nestor Lima. 


\section{INTRODUÇÃO}

Na história da educação brasileira e, sobretudo, na constituição moderna de escola, evidencia-se a influência de modelos e ideias que circulavam em um diálogo transnacional. Observamos que, especialmente, o contexto do final do século XIX e início do século XX, era permeado pela tentativa da construção de uma identidade nacional e da intenção de sistematizar a educação em seus diferentes níveis. Nesse sentido, as viagens pedagógicas se constituíram como um artifício utilizado pelos intelectuais da educação, na maioria das vezes, com o apoio dos governos, para buscar fora dos limites estaduais e nacionais ideias, modelos e experiências com intuito de aplicá-las nas realidades locais e contribuir assim para o avanço da educação brasileira.

Mignot (2010, p. 46) aponta que

Desde o final do século XIX, a arquitetura escolar, os livros, os cadernos, os métodos, os objetos didáticos, não escaparam do olhar atento de educadores brasileiros que cruzaram mares, para observar, comparar, buscar e propor inovações. Reconhecidos como especialistas pelos governos que os nomeavam para observar sistemas educacionais, suas viagens os legitimavam ainda mais no debate educacional.

Destacamos, porém, que as viagens pedagógicas não se iniciam com a República, mas já faziam parte das práticas incentivadas pelo governo ao longo do século XIX, por exemplo, com a participação de brasileiros em Exposições Internacionais. Mignot e Gondra (2007) demonstram que esta estratégia não foi utilizada apenas no Brasil, mas em outros países da Europa, como Portugal, Espanha e França. Educadores renomados ou anônimos, homens e mulheres, empreenderam diversas viagens em seus países, para outros vizinhos ou mais distantes, com a intenção de observar o que de mais novo se produzia em termos de educação.

A busca pelo inovador e pelo moderno marcaram, especialmente, as iniciativas político-educacionais nas primeiras décadas do século XX nos diversos 
estados brasileiros, entre eles, o Rio Grande do Norte. Nessa perspectiva, esse estudo toma como objeto a viagem pedagógica comissionada pelo Governo do Estado realizada pelo intelectual potiguar Nestor dos Santos Lima, no ano de 1923, que teve como destino os grandes centros educacionais do país, além da Argentina e do Uruguai.

Nestor dos Santos Lima se destacou no cenário estadual e nacional pela sua atuação enquanto educador, advogado e historiador, e pela sua participação nas diferentes e mais relevantes instituições educacionais e culturais do Estado durante a primeira metade do século XX. Nosso objetivo, ao longo deste trabalho, foi apresentar e analisar as representações do intelectual sobre a organização escolar nas Repúblicas do Rio da Prata a partir de sua viagem pedagógica às cidades de Buenos Aires e Montevidéu ${ }^{1}$.

Conforme explicitado por Vidal e Silva (2020), o interesse por novas tipologias de fontes permite novos olhares na História da Educação. Como produto de sua viagem, Nestor Lima apresentou um relatório intitulado " $\mathrm{Da}$ Organização do Ensino Normal, Profissional e Primário no sul do Brasil e no Rio da Prata”. É a partir da análise desse documento que construímos o nosso estudo e buscamos analisar as representações construídas pelo intelectual.

Nesse sentido, o conceito de representação se torna fundamental para a construção desse estudo, uma vez que conforme apreendemos de Roger Chartier, a escrita da viagem busca construir uma imagem a partir do real observado pelo viajante. Para Chartier (2017, p. 51-52)

As representações não são simples imagens, verdadeiras ou falsas, de uma realidade que lhes seria externa, elas possuem uma energia própria que leva a crer que o mundo ou o passado é, efetivamente, o que dizem que é. Nesse sentido, produzem as brechas que rompem às sociedades

\footnotetext{
${ }^{1} \mathrm{~A}$ construção deste artigo constitui-se como um desdobramento da pesquisa realizada ao longo do mestrado em educação que culminou com a produção da dissertação intitulada "As viagens pedagógicas de Nestor dos Santos Lima e a educação no Rio Grande do Norte na Primeira República” (AZEVEDO, 2020).
} 
e as incorporam nos indivíduos.

Desse modo, o relatório nos permite viajar com o intelectual e transitar pelos espaços que ele percorreu, compreender seus itinerários e seus percursos e nos aproximarmos das práticas observadas, mediadas pelas suas impressões e pela subjetividade do seu olhar impressa na sua escrita.

Para organização deste artigo, apresentaremos inicialmente quem era Nestor dos Santos Lima e sua relevância para a História da Educação do Rio Grande do Norte. Em seguida, apresentaremos o itinerário do intelectual em sua visita às cidades de Montevidéu e Buenos Aires, destacando os principais elementos elencados em seu relatório, os espaços que visitou, as práticas que observou, os profissionais que conheceu e encontrou. Por fim, apresentaremos algumas considerações sobre a análise realizada e a importância dessa viagem para a educação potiguar.

\section{O INTELECTUAL VIAJANTE}

Jean François Sirinelli (2003) exorta que o conceito de intelectual necessita ser compreendido pelo historiador a partir de uma concepção ampla e sociocultural, que englobe não apenas o envolvimento do sujeito, mas a influência que ele exerce enquanto criador e mediador cultural no contexto em que está inserido. É nesta perspectiva que, ao apresentarmos o potiguar Nestor dos Santos Lima, compreendemos que este se configura como um intelectual versátil e engajado socialmente.

Nestor dos Santos Lima, ou apenas Nestor Lima, (Figura 01) nasceu na cidade de Assú 2 no Estado do Rio Grande do Norte no ano de 1887. Formou-se na Faculdade de Direito de Recife em março de 1909. Encontramos indícios que

${ }^{2}$ A cidade de Assú localiza-se no interior do Estado do Rio Grande do Norte, região nordeste do país. 
nesse mesmo ano, Nestor Lima inicia o seu percurso no campo educacional com uma breve passagem como professor de lógica e literatura do Ateneu Norte Riograndense, instituição de ensino secundário da capital potiguar. Entretanto, é a Escola Normal de $\mathrm{Natal}_{3}$, que se tornará o principal campo de atuação do intelectual durante as décadas seguintes. A relação que Nestor Lima constrói com essa instituição marcou profundamente sua atuação intelectual, política e administrativa.

Figura o1 - Nestor dos Santos Lima.

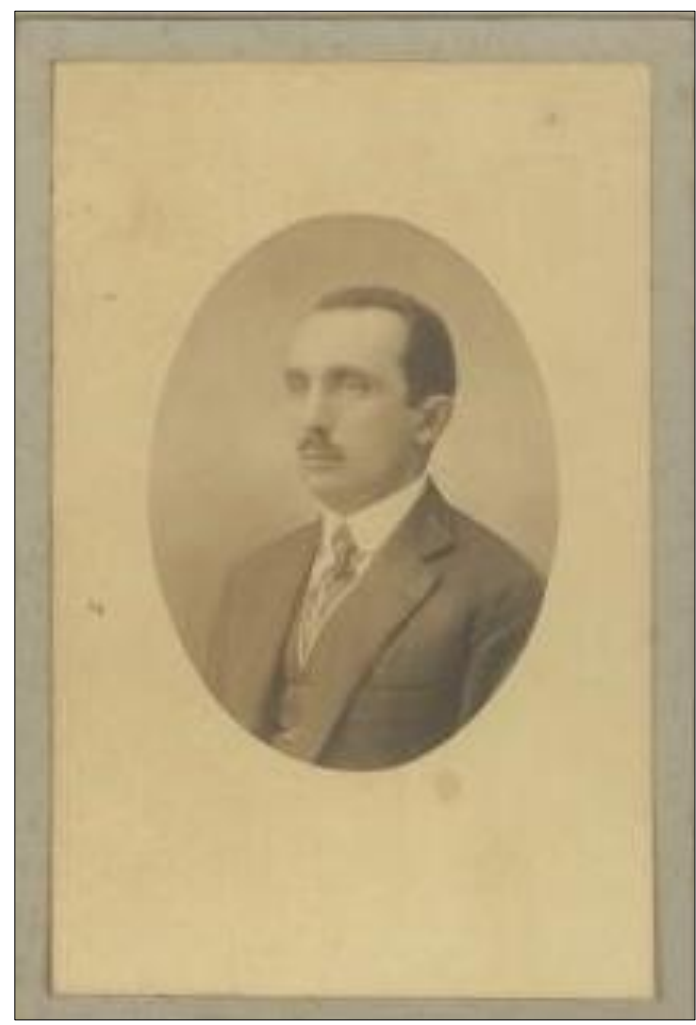

Fonte: Álbum de Fotografias do Instituto e Geográfico do Rio Grande do Norte - Escola Normal de Natal (1927).

Nestor Lima ingressou como professor de Pedagogia da Escola Normal em 1909 e, em 1911, se tornou o Diretor da Instituição, função que exerceu até o

3Sobre a Escola Normal de Natal e sua importância para a educação potiguar, consultar Nascimento (2018) "A Escola Normal de Natal (Rio Grande do Norte, 1908-1971)". 
ano de 1923. Nesse mesmo período, ocupou o cargo de Diretor do Grupo Escolar Modelo Augusto Severo que funcionava no mesmo prédio da Escola Normal e servia para a prática das normalistas.

Nestor Lima destacou-se no cenário potiguar enquanto advogado, historiador e professor. O intelectual transitou por diversos espaços na sociedade, integrando instituições científicas e culturais locais e nacionais. Nestor Lima se tornou sócio do Instituto Histórico e Geográfico do Rio Grande do Norte (IHGRN) em 1909. Segundo Souza (1987) foi por meio da conferência intitulada "A Matriz de Natal" que o jovem advogado se credenciou para ingressar naquela Instituição. Essa foi apenas uma das inúmeras contribuições de Nestor Lima para o Instituto. No IHGRN, ele desempenhou diversas atribuições, foi orador, secretário e redator da Revista e, no ano de 1927, foi eleito presidente da Instituição e, posteriormente, presidente perpétuo até sua morte, aos 72 anos, em 26 de fevereiro de 1959. Foi também membro da Sociedade Brasileira de Geografia, do Instituto Histórico e Geográfico Brasileiro e sócio de outros Institutos Históricos e Geográficos do país.

Em 1920, foi um dos fomentadores para a criação da Associação do Professores do Rio Grande do Norte. Já em 1936, foi um dos fundadores da Academia Norte-Rio-grandense de Letras. Enélio Petrovich (1987) aponta que, com a fundação da Academia, Nestor Lima ocupava a cadeira de número 09, sendo patrono o político potiguar, conhecido por ser abolicionista, Almino Álvares Afonso.

No ano de 1923, Nestor Lima deixou o cargo de Diretor da Escola Normal de Natal, para assumir, no ano seguinte, a função de primeiro Diretor do Departamento de Educação do Estado, permanecendo até o início de 1929. Sua atuação no campo educacional não se restringiu ao ensino primário e normal. Nestor Lima foi também Secretário Geral do Estado no período de 1930 a 1931. Em 1934, passou a ocupar a função de Procurador Geral do Estado e atuou como membro do Conselho Penitenciário de 1933 até 1936. Em 1949, o intelectual se tornou o primeiro Diretor da Faculdade de Direito de Natal. Nesta instituição 
Nestor Lima foi professor das disciplinas de Direito Internacional Público e Direito Penitenciário até o ano de 1951.

A produção intelectual de Nestor Lima é extensa. De acordo com Menezes (2015, p. 122) ele foi "autor de quarenta e oito publicações distribuídas em diferentes áreas, entre artigos de jornal, revistas, livros, conferências, entrevistas, relatórios e publicações oficiais". Ressaltamos que o intelectual encontrou espaço de escrita e fala nos jornais e impressos pedagógicos não apenas no Rio Grande do Norte, mas em outros Estados, publicando artigos e concedendo entrevistas, defendendo e disseminando suas ideias, sobretudo em relação ao ensino primário e normal.

Analisar o percurso profissional de Nestor Lima faz emergir a figura do intelectual viajante. Ele viajava para participar de eventos e congressos científicos como representante do Estado, do IHGRN e da Associação de Professores do Rio Grande do Norte. Como exemplo, podemos citar sua participação no Segundo Congresso Brasileiro de Instrução Primária e Secundária que ocorreu na cidade de Belo Horizonte, Minas Gerais, de 28 de setembro a 04 de outubro de 1912; no Quinto Congresso Brasileiro de Geografia realizado na cidade de Salvador em setembro de 1916; no Primeiro Congresso Brasileiro de Proteção à Infância (PCBPI), realizado no Rio de Janeiro no período de 27 de agosto a 05 de setembro de 1922, e na I Conferência Nacional de Educação realizada em Curitiba em 1927, entre outros.

Do mesmo modo, ressaltamos que Nestor Lima realizou duas viagens pedagógicas, comissionadas pelo governo do Estado, o que denota o reconhecimento do intelectual no campo educacional. A primeira viagem, realizada no ano de 1913, tinha como objetivo conhecer os melhoramentos técnicos adotados no ensino primário e normal no Rio de Janeiro e em São Paulo. O relatório desta viagem traz, em seus anexos, listas de livros comprados e recebidos em doação, além de materiais pedagógicos comprados pelo intelectual para serem utilizados nas instituições potiguares.

Dez anos após a primeira viagem, Nestor Lima realizou a segunda, sobre 
a qual o então governador do Estado Antônio José de Mello e Souza discorre4:

\begin{abstract}
Dirige ainda a Escola Normal o dr. Nestor dos Santos Lima, profissional dedicado e competentíssimo, a quem a Escola deve sobretudo a efficacia da sua organização e o brilho dos seus resultados. Conhecendo o valor da collaboração desse professor, incumbi-o em Maio ultimo de estudar, em commisão,os progressos do ensino, não somente no sul do paiz, como nas republicas do Prata, e dessa incumbência se desempenhou elle apresentando ao governo um relatario do que viu e observou, no qual temos a aprender e bastante a imitar (RIO GRANDE DO NORTE, 1923, p. 13).
\end{abstract}

O discurso do governador além de revelar aspectos políticos administrativos, interessa-nos, sobretudo, por mostrar o papel de destaque atribuído a Nestor Lima tanto na Escola Normal quanto na educação potiguar de um modo geral, o que possibilitou a expansão de sua atuação para além dos limites geográficos do estado. Na segunda viagem, realizada no ano de 1923, Nestor Lima visitou as capitais do Uruguai e da Argentina, e as cidades de São Paulo, Belo Horizonte, Rio de Janeiro e Vitória.

Em seu relatório de 1923, Nestor Lima traz apontamentos sobre o percurso e o retorno que nos fazem inferir que seu objetivo era também visitar outras capitais brasileiras. $\mathrm{O}$ autor justifica então a impossibilidade de ter realizado observações em outros Estados. Sobre cada um desses lugares, Nestor aponta os motivos pelos quais não foi possível realizar visitas ao Rio Grande do Sul, ao Paraná, a Santa Catarina, a Bahia e Pernambuco, além de Alagoas e Paraíba.

Notadamente fazia parte da estratégia da viagem pedagógica, o documento construído a partir da experiencia vivenciada. O relatório da viagem se apresenta assim, tanto como forma de divulgar o que havia sido conhecido

\footnotetext{
4Tendo em vista que, para este estudo, utilizamos como fontes documentos produzidos nas primeiras décadas do século XX, a escrita utilizada apresenta erros de grafia e incoerências em relação às normas ortográficas atuais. Optamos por fazer as citações reproduzindo fielmente $o$ que consta nos documentos.
} 
como de apontar as possíveis melhorias e o que deveria ser aplicado na educação local. Os relatos das viagens, muitas vezes publicados, revelam a materialização da experiência. Apreendemos com Certeau (2017, p. 183) que

\begin{abstract}
Todo relato é um relato de viagem - uma prática de espaço. [...] Essas aventuras narradas, que ao mesmo tempo produzem geografias de ações e derivam para os lugares comuns de uma ordem, não constituem somente um "suplemento" aos enunciados pedestres e às retóricas caminhatórias. Não se contentam em deslocá-los e transpô-los para o tempo da linguagem. De fato, organizam as caminhadas. Fazem a viagem antes ou enquanto os pés a executam.
\end{abstract}

Esse conceito fica ainda mais claro quando pensamos nos relatórios de viagens, que explicitam não apenas os lugares, mas os "espaços praticados". Os lugares enunciados pelo intelectual ganham vida à medida que eles os visita. Nessa perspectiva, acompanhamos, na seção que se segue, Nestor Lima em sua viagem por Montevidéu e Buenos Aires, buscando apreender as representações do intelectual sobre a organização da educação nesses espaços.

\title{
O OLHAR DE NESTOR LIMA À ORGANIZAÇÃO ESCOLAR NO RIO DA PRATA
}

O relato da viagem implica, ao mesmo tempo, em uma produção com caráter oficial, mas perpassada pela subjetividade do autor. Nesse sentido, Silva (2013, p. 120) exorta que "em escritas de viagem, a narrativa e a memória são elementos constituintes da prática de registrar, em que o fio condutor é a própria travessia". Assim, o enfoque da escrita diz respeito ao percurso trilhado ao longo da viagem, as pessoas encontradas, a acolhida, as instituições e as aulas observadas, a estrutura dos espaços e as impressões do intelectual sobre as práticas educacionais que teve contato. $\mathrm{O}$ relatório legitima e materializa a viagem e a experiência de Nestor Lima nesses espaços (Figura 02). 
Figura o2 - Capa do Relatório "Da Organização do Ensino Normal, Profissional e Primário no sul do Brasil e no Rio da Prata" (LIMA, 1923).

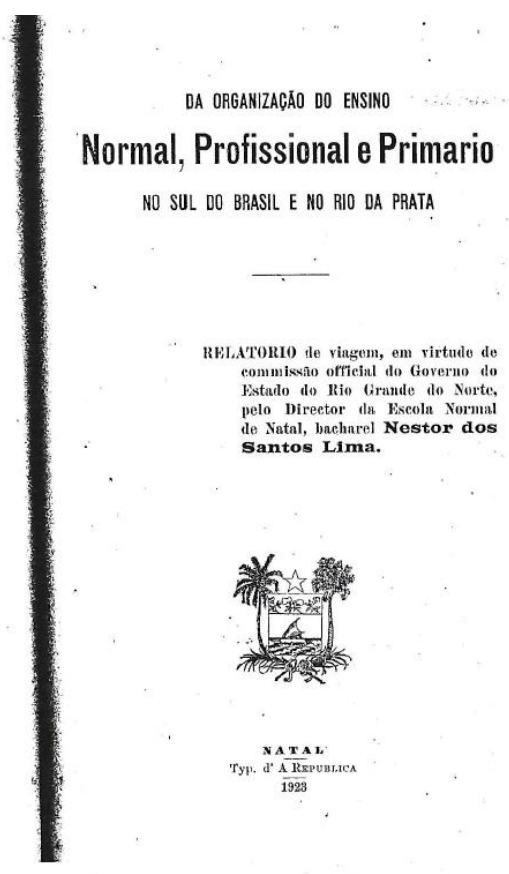

Fonte: Repositório de História e Memória da Educação - RHISME/UFRN.

O relatório produzido por Nestor Lima, publicado pela Tipografia do Jornal A República, que era órgão oficial da imprensa do Estado, é composto por cento e vinte e cinco páginas. O documento traz elementos que explicitam o objetivo de sua produção desde o título - relatório de viagem, quem o produziu e seu cargo - diretor da Escola Normal de Natal, bacharel Nestor dos Santos Lima. O autor dividiu o relatório em cinco partes: Preâmbulo, Intercâmbio pedagógico, As organizações escolares no Rio da Prata, Nos Estados do Sul do Paiz e Impressões Geraes. Nos deteremos a segunda seção do documento.

Ao relatar seu percurso de viagem em Montevidéu e em Buenos Aires, Nestor Lima menciona diversos nomes de profissionais da educação destes países que também apresentamos neste trabalho. Com alguns desses sujeitos, o intelectual teria tido contato anterior ao participar do Primeiro Congresso Brasileiro de Proteção à Infância (PCBPI), realizado no Rio de Janeiro no período de 27 de agosto a 05 de setembro de 1922. 
A este respeito, defendemos a hipótese de que este evento foi o ponto de partida para a viagem que se realizaria no ano seguinte, uma vez que nesse espaço de discussão, o intelectual pôde assistir a debates sobre os trabalhos de profissionais da educação que atuavam no Uruguai e na Argentina. Do mesmo modo, compreendemos que, por já terem participado de um evento científico no Brasil, estes profissionais da educação já haviam iniciado a construção de um diálogo entre os intelectuais da educação para além das fronteiras nacionais.

É a partir do relato do autor que identificamos que sua viagem se inicia no dia 03 de março de 1923, data em que é publicado o ato do governo incumbindo-o de realizar a sua segunda viagem pedagógica com o intuito de observar a organização do ensino normal e profissional. Nestor Lima deixa claro que foi decisão sua abranger também o ensino primário em suas observações (LIMA, 1923). Embora o intelectual não mencione a data de sua partida em seu relatório, encontramos na Revista do IHGRN (1923) menção ao seu pedido de afastamento de suas funções nesta instituição pelo período de quatro meses e a data de 06 de março referente a sua saída de Natal.

\section{“OBSERVAÇÃO PARA AS COISAS DO ENSINO" NA CAPITAL URUGUAIA}

Nestor Lima (1923, p. 10) declara sobre sua chegada ao Uruguai que, "a primeira cidade que visitei, com espirito de observação para as coisas do ensino, foi Montevideo, aonde cheguei, a bordo do trans atlântico allemão "Cap Polonio", na noite de 2 de maio do corrente ano". Ao discorrer sobre o período que permaneceu na cidade, Nestor Lima aponta os espaços que visitou, as pessoas que encontrou, além de explicitar as suas impressões sobre aquilo que observou.

Encontramos no relatório a menção a dez diferentes instituições e espaços: 
1. Escuela Normal para Niñas;

2. Escuela de applicación para Niñas;

3. Escuela de pratica para candidatos nacionales;

4. Escuela de $2^{\circ}$ grado $n^{0} 22$;

5. Escuela de applicación para varones;

6. Instituto Nacional de Niñas surdo-mudas;

7. Escuela en aire libre;

8. Escuela de pratica $\mathrm{n}^{\circ} 14$, de primer grado;

9. Museo pedagogico e Bibliothecapedagogica;

10. Centro de Cultura Physica.

Seu relato detalhado acerca de sua visita ao Uruguai aponta os endereços dos locais que visitou e os profissionais com os quais teve contato, cujos nomes e funções apresentamos no quadro 01.

Quadro o1 - Profissionais citados por Nestor Lima em sua visita a Montevidéu (1923).

\begin{tabular}{|c|c|}
\hline NOME & FUNÇÃO/CARGO \\
\hline Juan Aguirre Gonzalez & $\begin{array}{l}\text { Presidente do Conselho Nacional de Ensino } \\
\text { Primário e Normal }\end{array}$ \\
\hline Emilio Fournié & $\begin{array}{l}\text { Inspetor técnico geral do Ensino primário e } \\
\text { normal }\end{array}$ \\
\hline Leonor Horticou & Diretora da Escola Normal para Niñas \\
\hline Izabel de La Fuente & $\begin{array}{l}\text { Professora de } 3^{\circ} \text { grau - classe de língua } \\
\text { castelhana }\end{array}$ \\
\hline Julio de La Fuente & Professor - classe de agricultura \\
\hline Aurora Valazco de Brunetti & Diretora da Escuela de Applicacion para Niñas \\
\hline Maria E. de Castro & Professora $1^{\circ}$ ano infantil - aula de linguagem \\
\hline Thereza Buscazzo & $\begin{array}{l}\text { Diretora da Escuela de pratica para } \\
\text { candidatos nacionales }\end{array}$ \\
\hline Delfina Calvo & Diretora da Escuela de $2^{\circ}$ grado n. 22 \\
\hline Dinah Castro & Professora - classe de cozinha \\
\hline ArthuroCarbonell y Migall & $\begin{array}{l}\text { Diretor da Escuella de Aplicacion para } \\
\text { Varones }\end{array}$ \\
\hline
\end{tabular}




\begin{tabular}{|l|l|}
\hline Julio de la Fuente & $\begin{array}{l}\text { Sub-diretor da Escuella de Aplicacion para } \\
\text { Varones }\end{array}$ \\
\hline Anna B. Scarrone & $\begin{array}{l}\text { Diretora do Instituto Nacional de } \\
\text { NiñasSurdo-mudas }\end{array}$ \\
\hline Pilar Llache de Duza & Diretora da Escuelaen Aire Libre $\mathrm{n} 3$ \\
\hline Juan Aguirre Gonzalez & $\begin{array}{l}\text { Presidente do Consejo Nacional de Enseñanza } \\
\text { Primaria y Normal }\end{array}$ \\
\hline Maria Manoela Zapater & $\begin{array}{l}\text { Regente da Classe de Anormaes da Escuela de } \\
\text { Pratica n } 14\end{array}$ \\
\hline
\end{tabular}

Fonte: Elaborado a partir do Relatório de Viagem (LIMA, 1923)

Ao escrever seu relatório, Nestor Lima opta por utilizar alguns termos em espanhol ao apresentar o nome das escuelas, ao se referir às niñas, varonese maestros, além de situar o endereço dos espaços mencionando a calleem que está situada. Compreendemos que esta escolha do autor reflete a aproximação que Nestor Lima busca demonstrar com a cultura e com o idioma dos países que visitou, além de conferir ao seu relato credibilidade e de legitimar o seu papel no desempenho de sua função a cargo do Estado. O pensamento de Certeau (1982, p. 100) corrobora com esta percepção à medida que o autor considera que "a linguagem citada tem por função comprovar o discurso: como referencial, introduz nele um efeito de real; e por seu esgotamento remete, discretamente, a um lugar de autoridade".

Ressaltamos que, conforme nos aponta Chamon e Faria Filho (2010, p. 19) "o relatório era uma prestação de contas ao governo de sua viagem comissionada, ao mesmo tempo em que era o momento de compartilhar percepções, opiniões e conhecimentos sobre um outro com seus contemporâneos". Desse modo, destacamos que as escolhas do autor na produção de seu relato de viagem possuem uma intencionalidade, a sua escrita não é neutra e a linguagem utilizada remete a um lugar de autoridade frente aos seus leitores.

Observamos a preocupação do intelectual em conhecer a organização geral do ensino no país e na capital, apresentando-a em seu relatório. De acordo 
com Nestor Lima, em relação ao ensino normal, este era oferecido em três graus, sendo apenas o de $1^{\circ}$ grau composto por um curso de quatro anos seguidos e mais complexo, ao contrário dos de $2^{\circ}$ e $3^{\circ}$ grau que poderiam ser realizados em dois anos sem tanto rigor. Existiam no Uruguai duas classes de professores: os normalistas formados nas Escolas Normais oficiais e os nacionaes que estudando em outras instituições deveriam se submeter a exames trimestrais perante as escolas oficiais.

Quanto a formação prática, Lima (1923, p. 12) aponta a diferença para as duas classes de professores, enquanto os normalistas a realizariam nas escolas de aplicação, os candidatos à "maestros nacionales se exercitam em escolas comuns, para isso designadas previamente".

Quanto a organização do ensino primário, Nestor Lima aponta que este compreendia três graus distribuídos em oito anos, sendo o $1^{\circ}$ grau formado do $1^{0}$ ao $4^{\circ}$ ano, o $2^{\circ}$ grau pelo $5^{\circ}$ e $6^{\circ}$ ano, e o $3^{\circ}$ grau pelo $7^{\circ}$ e $8^{\circ}$ ano. Para atuar nas escolas primárias, os professores formados no ensino normal deveriam se submeter a concursos. $\mathrm{O}$ autor acrescenta ainda que "além destas, possue o Uruguay as escolas de Surdo-mudos, uma para meninos e outra para meninas e moças, escolas ao ar livre para débeis, classes montessorianas para atrazados e anormaes" (LIMA, 1923, p. 13).

A subjetividade na escrita permeia o relato da viagem, bem como as preferências e as concepções teóricas do intelectual. Assim, destacamos a atenção que Nestor Lima concebe aos aspectos referentes a estrutura dos prédios e das salas, com foco nas condições relativas ao higienismo, sobretudo quanto ao tamanho das salas e a iluminação.

Observamos que a concepção higienista relacionava-se, nas primeiras décadas do século $\mathrm{XX}$, a perspectiva de modernidade privilegiada no período. Sobre esse aspecto, Menezes exorta que

Sanear as cidades, modelar os costumes, disciplinar as populações, higienizar a sociedade de todos os males que obstam o progresso são 
Nesse sentido, ao se referir, por exemplo, a Escuela Normal para Ninãs que foi sua primeira visita, Nestor Lima descreve "o prédio é de dois pavimentos, pouco amplo, de luz soffrível, e muito próximo de rua de grande movimento de viaturas: há ruídos proximos que perturbam o trabalho escolar" (LIMA, 1923, p.13). Em outro momento, o autor menciona que a Escuela de pratica para candidatos nacionales "é um prediotypico das escolas modernas de Montevideo: construído especialmente, com dois pavimentos, systema de vastos corredoresgalerias, tendo ao lado as classes. Tem pateo livre e amplo para recreio e possue arvores" (1923, p. 17).

Nesse ponto, é importante destacar que o olhar do intelectual em sua viagem volta-se para as representações do moderno no campo educacional. Para Le Goff (1990), o conceito de modernidade é fruto dos ideais iluministas que se desenvolveram ao longo do século XIX e início do século XX. Para o autor, essa modernidade que se tornou sinônimo de progressista, "nasce do sentimento de ruptura com o passado" (LE GOFF, 1990, p. 169).

Observamos, assim, que nos deparamos com um momento histórico em que se propõe uma transformação, que se deseja ao mesmo tempo denegrir e se afastar daquilo que é tido como antigo e superado. Essa modernidade, no início do século XX, busca se efetivar especialmente na configuração das cidades, na política, na economia e na educação.

Assim, a modernidade pedagógica encerra uma compreensão de escola e de ensino, em que concentram esforços e atenção à estrutura dos prédios, à constituição das salas, à organização do espaço e dos materiais, que seriam fundamentais para proporcionar uma educação completa ao aluno. Essa educação deveria envolver aspectos intelectuais, físicos e morais dos alunos, 
materializando-se na organização das disciplinas.

Nessa perspectiva, identificamos que Nestor Lima também se detém a apresentar a organização dos programas de disciplinas do ensino primário, citando que estas correspondiam ao que havia sido aprovado pelo governo Uruguaio em 11 de janeiro de 1916.

Ao longo de sua visita, Nestor Lima busca realizar a comparação entre aquilo que observa e a realidade brasileira e local. Isto é evidenciado quando o autor aponta que "as linhas geraes dos methodos usados não discrepam dos que já são praticados no Brasil" (LIMA, 1923, p. 14) ou quando afirma que "a pratica escolar, ou melhor, a aprendizagem da technica pedagógica está ali, porém, mais bem apurada que entre nós" (1923, p. 15).

Percebemos assim, que o intelectual busca assumir uma postura crítica frente àquilo que observa nos espaços pedagógicos que visitou em comparação com o seu contexto educacional. Nestor Lima demonstra, em seu texto, que sua visão dessa viagem se refere a um intercâmbio pedagógico, ao mesmo tempo em que buscava observar e aprender sobre as práticas realizadas nos locais que visitou, assumia que também tinha o que contribuir a partir de sua própria experiência profissional.

Em seu relato sobre a visita à Escuela de Aplicacion para Niñas, o intelectual aponta que

Fui, afinal, convidado para fallaráquella classe: accedi e fallei em vernáculo brasileiro, a pedido insistente das ouvintes. Comecei recordando que áquella hora, eram quatro horas em Natal, estaria eu em face das minhas alunnas do $4^{\circ}$ anno a dizer-lhes o que me convidavam a dizer ali: a opinião acerca de methodos da leitura inicial. [...] Depois de mais de vinte minutos de exposição, dei por finda a cooparticipação na critica. Recebi gentis parabens e agradecimentos, enquanto que a Directora pedia-me que la voltasse para continuar a troca de ideias e pontos de vista profissionaes (LIMA, 1923, p. 16-17, grifo do autor). 
O intelectual pôde observar diferentes aulas nas instituições que visitou, linguagem, agricultura, cozinha, artes manuais, entre outras. Destacamos que Nestor Lima, ao visitar a Escuela de Applicación para Varones, observou a classe de slojd que o autor define como um "systhema de trabalho manual sueco, hoje tão conhecido e universalizado, o qual consiste na utilização da madeira e outros instrumentos da carpintaria [...] a fim de serem aplicadas as regras da geometria" (1923, p. 20). 5

Interesse especial percebemos no intelectual ao visitar no Uruguai instituições designadas por ele como cursos especiaesque "se destinam a aproveitar as creançasatrazadas ou anormaes, e destes os profundos, como os surdos-mudos, educando-lhes a intelligenciaatrophiada e proporcionando-lhes um officio que lhes assegure vencerem na lucta social" (LIMA, 1923, p. 21).

Ao se referir ao Instituto Nacional de NiñasSurdo-mudas, Nestor Lima aponta que existiam cerca de cem meninas que viviam na instituição e que lá aprendiam "o saber e a trabalhar" (1923, p. 21). O autor menciona a existência de aulas de linguagem, oficinas de cipó ou vime, oficinas de flores, oficina de lã e desenho artístico. Observa-se o caráter preparatório para o trabalho apontado pelo intelectual.

Sobre esta visita, Nestor Lima se diz encantado e utiliza diversos adjetivos para descrevê-la, concluindo que estava convencido "da possibilidade de educação dos anormaes profundos" (LIMA, 1923, p. 23). O intelectual menciona ainda que o curso normal para os professores deste ensino incluiria aulas de pedagogia especial, anatomia, psicologia e higiene.

Outra instituição visitada por Nestor Lima se refere a Escuelaen Aire Libre sobre a qual o autor aponta que nada tinha de especial quanto ao ensino, mas que as aulas eram realizadas ao ar livre para os "75 alunnos débeis" (1923, p. 25). Essa escola, que funcionava em regime de externato, estava sob a direção de 
um profissional da Liga Uruguai contra a Tuberculose.

Nestor Lima menciona ainda as Classes de anormais como uma tentativa para educar aqueles que, por meio de exames médicos, eram considerados instáveis ou apáticos. Ao descrever sua visita em uma classe localizada na Escuela de pratica n.14, o intelectual faz questão de elencar os materiais montessorianos que encontrou.

Ao se referir a essas três últimas instituições, Nestor Lima se atem aos detalhes, registrando desde os tipos de aulas ministradas, alguns materiais encontrados, a estrutura das escolas e a sua percepção quanto a alguns alunos, como encontramos na seguinte descrição

\begin{abstract}
Aqui uma creança de oito annos, mirradinha, de rosto coberto de sardas e espinhas, tem os movimentos incertos arithmicos de um desequilibrado; ali, outra tem os movimentos lentos e demorados, de um imbecil; aqui, outro é um typo de bôbo, aos 14 annos, já púbere, ri de tudo e têm a physionomiatypica dos anormaes; afinal surge um pretinho - Baêza - refugo das escolas comuns, onde era a causa da desordem permanente e a quem tudo de mal se atribuía invariavelmente. Este tem um anno de classe e já tem melhorado sensivelmente; ele que nada lia nem escrevia, faz bem e correctamente, na minha presença, um didacto, leu um trecho de um livro (LIMA, 1923, p. 27).
\end{abstract}

A observação da organização do ensino Uruguaio realizada por Nestor Lima contemplou também as visitas ao Museo Pedagogico e a Bibliotheca Pedagogica. Em relação a esses espaços, constatamos no relatório do intelectual, os elogios que ele faz a essas iniciativas, declarando inclusive, sobre a biblioteca, se tratar de "um bello esforço em prol da educação popular e um ainda mais bello exemplo a ser imitado" (1923, p. 29).

É interessante notar o destaque que Nestor Lima confere, em seu relatório, às suas impressões pessoais quanto a vestimenta feminina exigida socialmente e dentro do ambiente escolar, seja para professoras ou para alunas. Essa relevância atribuída pelo intelectual ao vestir orientou também sua escrita 
na Revista Pedagogium da Associação de Professores do Rio Grande do Norté ${ }^{6}$ Neste impresso, encontramos um artigo de Nestor Lima intitulado “As modas e a Educação”, no qual ele afirma que "o palpitante assumpto das modas femininas está intimamente ligado á questão educativa” (LIMA, 1921, p. 15). Para Nestor Lima, o vestir feminino associava-se a educação moral, ao pudor e á higiene. É a partir dessa perspectiva, que o intelectual elogia essa virtude do trajar do povo uruguaio.

Por fim, destacamos que Nestor Lima enaltece as iniciativas uruguaias quanto a existência de um cinema educativo, do Centro de Cultura Physica, pelo incentivo ao ensino do desenho e pela realização de cursos de férias direcionados aos professores das escolas públicas. Sobre estes últimos, o intelectual considera que poderiam ser convenientes adotados na realidade potiguar.

Com base no pensamento Azevedo (2020), evidencia-se o movimento de apropriação das ideias e práticas observadas por Nestor Lima em sua viagem no contexto da educação potiguar. O que nos remete a compreensão proposta por Chartier sobre a apropriação que se refere, principalmente, as condições de possibilidades existentes, aos usos diversos e as interpretações (CHARTIER, 1991).

Nesse sentido, a autora, ao discorrer sobre a influência e apropriação das viagens pedagógicas de Nestor Lima na educação potiguar, aponta que "na gestão enquanto Diretor do Departamento de Educação, Nestor Lima pôde promover junto aos educadores potiguares o Curso de Férias nos anos de 1925 e 1926, previsto conforme a Lei no 595, de 5 de dezembro de 1924" (AZEVEDO, 2020, p. 158).

\footnotetext{
${ }^{6}$ A Associação de Professores do Rio Grande do Norte foi criada em 04 de dezembro de 1920, com o objetivo de defender a educação e o fortalecimento do magistério. Sobre essa instituição, consultar conferir dissertação de Francisca Wilma Cavalcante, "Associação de Professores do Rio Grande do Norte: a missão de educar (1920-1933). A Associação publicou, a partir de 1921, um impresso denominado Pedagogium, do qual Nestor Lima foi diretor no período de 1921 a 1923. Discutimos a relação de Nestor e a Revista Pedagogium no trabalho intitulado "Nestor dos Santos Lima e a Revista Pedagogium (1921 - 1924): lugar de fala, prática e escrita" apresentado no X Congresso Brasileiro de História da Educação (X CBHE - 2019).
} 


\section{“OBSERVAÇÃO PARA AS COISAS DO ENSINO” EM BUENOS AIRES}

Ao deixar Montevidéu, Nestor Lima se dirigiu então a Buenos Aires onde ficou no período de 10 a 17 de maio de 1923. Do mesmo modo que o intelectual apresentou os sujeitos que encontrou em sua visita a Montevidéu, também o faz em relação a sua visita a capital argentina, apesar de não mencionar alguns nomes de diretores das instituições visitadas (Quadro 02).

Quadro 02 - Profissionais citados por Nestor Lima em sua visita a Buenos Aires (1923).

\begin{tabular}{|l|l|}
\hline \multicolumn{1}{|c|}{ NOME } & \multicolumn{1}{c|}{ FUNÇÃO/CARGO } \\
\hline Alcino dos Santos Silva & Consul Brasileiro \\
\hline Enrique Loudet & $\begin{array}{l}\text { Médico, pertencente ao Corpo Médico Escolar } \\
\text { do Conselho Nacional de Educação }\end{array}$ \\
\hline José Rezzano & Inspetor técnico das Escolas da Capital \\
\hline Francisco Herrera & $\begin{array}{l}\text { Professor, subinspetor técnico das Escolas da } \\
\text { Capital }\end{array}$ \\
\hline Eloy Fernandes Alonso & Professor, inspetor primário \\
\hline Aldo Banchero & Professor, inspetor primário \\
\hline JulioPicarel & Inspetor de ensino \\
\hline Alfredo G. Villalba & Diretor Escuela Normal de Varones \\
\hline Salvador Pizzuto & $\begin{array}{l}\text { Professor Normal, Diretor da Escola } \\
\text { Presidente Roca }\end{array}$ \\
\hline
\end{tabular}

Fonte: Elaborado a partir do Relatório de Viagem (LIMA, 1923)

Nestor Lima preocupa-se em apresentar em seu relatório a organização geral do ensino argentino, sobretudo em relação ao ensino primário, mencionando as leis que regulamentavam. Do mesmo modo, o intelectual apresenta a organização das Escolas Normais, ressaltando que estas tinham como base o Instituto Normal de Buenos Aires, fundado em 1874 e o de Paraná, da província de Entre-Rios fundado por Domingo Sarmiento em 1869. Nestor Lima aponta a existência de 86 escolas normais na Argentina, divididas em três 
categorias: as de preceptores, para as escolas rurais; as de maestros, para os diversos graus de ensino; e as de professores, para o ensino primário integral.

Nestor Lima cita ainda a existência de uma Escola Normal para professores de Linguas-vivas (francês e inglês), e do Instituto Nacional Superior de Educação Physica, fundado em 1909. Quanto às escolas profissionais, o intelectual aponta que o ensino profissional de artes e ofícios era oferecido a partir de dois tipos de escola: as Industriais da Nação e as profissionaes complementares.

Ao analisarmos sua escrita, emergem as preferências do intelectual na escolha dos espaços que visitou. Nesse sentido,Silva (2013) aponta a circulação das ideias, as novidades pedagógicas e o intercâmbio como motivações dos intelectuais interessados na educação ao viajar. O interesse de Nestor Lima em relação a capital argentina é evidenciado desde o princípio do relato sobre essa etapa da viagem, uma vez que ele faz questão de ressaltar que

\footnotetext{
Um dos mais antigos anceios de minha carreira no ensino era conhecer de perto o adeantado centro de cultura, que é a capital da Republica Argentina. Acostumado a admirar os seus progressos nos diversos aspectos da sua civilização aprimorada, desejava, desde muito, pôr-me em contacto com aquelle povo irmão e com seus institutos pedagogicos. Realizei isto agora (LIMA, 1923, p. 34).
}

Assim, em Buenos Aires, Nestor Lima visitou escolas primárias, normais e profissionais, conforme listadas.
1. Escuela General San Martin
2. Escuela Estados Unidos del Brasil
3. Escuela Normal de Varones
4. Escuela complementaria Presidente Roca - ensino profissional
5. Escuelas complementarias Masculina e Feminina. 
A primeira escola visitada por Nestor Lima foi a escola primária "General San Martin”, na qual o intelectual observou aulas de leitura e escrita, matemática, geografia e castelhano. Na Escuela Estados Unidos del Brasil, por sua vez, o intelectual não faz menção às aulas. Em relação aos dois prédios, Nestor Lima ressalta que estes poderiam ser melhores. Em suas visitas às escolas primárias, o intelectual relata o tratamento recebido e as homenagens feitas ao Brasil por meio da decoração das salas, do canto ao hino nacional, de poesias e cartas endereçadas as alunas e escolas brasileiras.

Ainda em relação ao ensino primário argentino, Nestor Lima demonstra o seu interesse sobre a organização deste, especificando a divisão das disciplinas, a organização das aulas e das salas, a constituição do magistério e as festas escolares existentes.

Ao descrever sua visita a Escuela Normal de Varones, o intelectual demonstra a sua admiração e entusiasmo com a instituição.

\footnotetext{
O vasto e bello prédio em que está installada a afamada Escola, de onde tem irradiado um grande movimento pedagógico, acha-se provido de material extenso e apropriado, comprehende desde as salas de canto, os gabinetes de physica, chimica e historia natural, as salas de desenho, trabalho manual, de carpintaria, slojd, pateos de gymnastica, segundo o systhema nacional argentino, de tudo quanto é possível e necessário á realização de um curso normal eficaz (LIMA, 1923, p. 41-42).
}

Nestor Lima faz questão de mencionar seu diálogo com o diretor da instituição, enfatizando as relações amistosas entre os dois países. Destarte os elogios à estrutura, o intelectual ressalta que "nas aulas normaes os processos não discrepam dos que já conhecemos” e, após detalhar os programas e planos da escola, considera que complexos e amplos "ainda assim, não me parece completo, dada a largueza do trabalho que a Argentina vem realizado no ensino nacional" (LIMA, 1923, p. 44).

Em Buenos Aires, Nestor Lima visitou também Escuelas Complementarias, que conforme apontado pelo intelectual se referiam a um 
modelo de ensino profissional que "sem serem Escolas Industriaes, todavia, fornecem preparação profissional, em horários apropriados e nos edifícios das escolas primárias comuns" (LIMA, 1923, p. 45). O intelectual apresenta interesse por essa modalidade de escola, tendo visitado a Escola Presidente Roca que serviu de modelo inicial. Segundo Lima, existiam em Buenos Aires 56 cursos complementares.

Ao visitar as Escuelas complementarias masculina e feminina, Nestor Lima observou a organização das aulas e do prédio, mencionando a existência de classes de tecelagem, bordado, francês, inglês e castelhano, na seção feminina; desenho geométrico, marcenaria (slojd), datilografia, telegrafia e telefonia, francês, inglês e castelhano, na seção masculina. O curso oferecido nessas escolas permitia ao aluno receber um certificado de aptidão na especialidade de acordo com o grupo de disciplinas cursadas.

Ao fim desta parte do seu relato, Nestor Lima afirma que não teve "ensejo de visitar a Escuela Industrial de la Nacion” com a justificativa que este modelo não poderia ser imitado pelo Rio Grande do Norte. Sua fala demonstra o interesse em que este modelo de escolas complementares fosse apropriado no Rio Grande do Norte.

Sua preocupação em descrever a organização do ensino, citar objetivos e reproduzir programas, além de ter direcionado sua visita às instituições específicas, demonstra o seu interesse em fornecer subsídios para a reorganização da educação potiguar. Ao final do seu relatório, ao se referir ao ensino argentino, Nestor Lima ressalta

Muito nos converia olharmos para este bello exemplo e procurar seguilo. Suas escolas primárias e seus cursos profissionaes e complementares, estes especialmente, merecem imitação, ou melhor adaptação ao nosso meio, tal é a segurança de sua finalidade e a praticabilidade de sua organização entre nós (LIMA, 1923, p. 119).

O intelectual menciona ainda a existência na Argentina de escolas para 
débeis, de colônias de férias e de sociedades cooperadoras com o objetivo de ajudar com alimentação e vestuário de crianças pobres. Nestor Lima ressalta o interesse, esforços e participação do Estado e da Sociedade com o objetivo de promover o progresso das escolas primárias Argentinas, além de ressaltar a atuação do Conselho Nacional de Educação que, por meio de seus presidentes, tem a sua grandeza "pela actuação directa que exerceram na formação mental da nação argentina" (LIMA, 1923, p. 50).

Nestor Lima encerra seu relato sobre a viagem a capital argentina apontando o seu interesse pela cultura da cidade ao descrever sua visita ao Jardim Zoológico, ao Museu Histórico Argentino e ao Teatro Colón. No dia 17 de maio, o intelectual conclui então essa parte de sua viagem pedagógica às Repúblicas do Rio da Prata, retornando ao Rio de Janeiro.

\section{CONSIDERAÇÕES FINAIS}

Compreendemos que as viagens pedagógicas não são elementos isolados, mas parte de um conjunto de ações políticas. Fruto de interesses políticos e administrativos, a viagem comissionada de Nestor dos Santos Lima fez parte de projetos oficiais do governo potiguar com vistas a reorganização da educação potiguar. Nosso estudo permite assim compreender as articulações na busca pela instauração de um modelo de educação e organização de um sistema de ensino no Rio Grande do Norte nas primeiras décadas do século XX.

Este estudo teve como objetivo apresentar e analisar as representações do intelectual Nestor Lima sobre a organização escolar nas Repúblicas do Rio da Prata a partir de sua viagem pedagógica às cidades de Buenos Aires e Montevidéu no ano de 1923. Ressaltamos, assim, a relevância e a potencialidade dos relatos de viagens como fontes para a História de Educação. O olhar atento dos intelectuais viajantes e a escrita pormenorizada permite ao pesquisador o acesso a uma diversidade de informações. 
A partir de seu relatório de viagem, nos aproximamos dos espaços que visitou, dos sujeitos que conheceu e das práticas que observou. Identificamos os elementos da organização do ensino em Buenos Aires e Montevideo, por meioda percepção do intelectual expressa em sua escrita.

Notadamente, evidencia-se os interesses particulares e profissionais do intelectual na escolha dos espaços e instituições que visitou. Sua relação com o ensino primário e com o ensino normal orientaram suas visitas. Destarte, evidencia-se também o seu interesse por outras experiências educacionais específicas, a exemplo das escolas para anormais e as escolas complementares.

Trazemos elementos que podem auxiliar na investigação acerca da circulação de ideias educacionais a partir do diálogo entre o Brasil, a Argentina e o Uruguai no período. Circulação essa promovida, especialmente, pelos sujeitos que viajavam para participar de eventos ou observar as práticas educacionais com o intuito de reproduzi-las.

Ao longo de seu relato, o intelectual aponta diversos nomes de profissionais com os quais teve contato. Destacamos que alguns desses sujeitos haviam participado de evento realizado no Brasil no ano anterior. Incorporamos os nomes e suas funções, tal qual mencionado pelo autor, uma vez que compreendemos a importância das teias, das relações construídas entre os sujeitos. Sistematizar essas informações poderá servir como base para futuros estudos acerca das sociabilidades intelectuais entre educadores dos três países.

Observamos que Nestor Lima constrói a sua escrita a partir de seus interesses, sendo mais detalhista ou mais objetivo. Destacamos a importância que o intelectual atribui aos aspectos estruturais dos prédios e das salas, com foco nas condições relativas ao higienismo. Do mesmo modo, ele se preocupa em incorporar ao seu relato descrições detalhadas da organização do ensino nas localidades, com programas completos dos cursos.

Outro aspecto que ganha ênfase na escrita do intelectual sobre a viagem a Montevidéu e Buenos Aires diz respeito aos materiais pedagógicos utilizados 
nas diferentes instituições, uma vez que estes conferem a feição moderna a educação.

Conforme apontado pelo intelectual, evidencia-se a percepção de Nestor Lima em relação a viagem como um intercâmbio pedagógico, à medida que objetivava observar e aprender sobre as práticas educacionais, também assumia a postura de autoridade em relação ao ensino, sobretudo primário e normal.

Destacamos, por fim, que duas experiências atraíram a atenção do intelectual e que ele estimulou a adequação na organização do ensino potiguar: os cursos de férias das escolas de Montevidéu e as escolas complementares argentinas. Nestor Lima operacionaliza essas ideias, propondo a adequação diante do que era possível considerando os recursos financeiros e de pessoal, estruturais e culturais potiguares.

No ano seguinte a realização desta viagem, o intelectual assume a Diretoria do Departamento de Educação do Estado e seus esforços concentramse na organização do ensino. Compreendemos que as observações que realizou nas Repúblicas do Rio da Prata influenciaram as suas ideias educacionais que seriam materializadas em legislações e regimentos, no intuito de conferir uma feição moderna ao ensino potiguar.

\section{REFERÊNCIAS}

AZEVEDO, Laís Paula de Medeiros Campos. As viagens pedagógicas de Nestor dos Santos Lima e a educação no Rio Grande do Norte na Primeira República. 19of. Dissertação (Mestrado em Educação) - Centro de Educação, Universidade Federal do Rio Grande do Norte, Natal, 2020.

CERTEAU, Michel de. A Escrita da História. Tradução de Maria de Lourdes Menezes. Rio de Janeiro: Forense-Universitária, 1982. 181

CERTEAU, Michel de. A invenção do cotidiano: 1 . Artes de fazer. Tradução de Ephraim Ferreira Alves. 22.ed. Petropólis, RJ: Vozes, 2017. 
CHAMON, Carla Simone; FARIA FILHO, Luciano Mendes. O olhar comparativo: Estevão de Oliveira e os grupos escolares em Minas, no Rio e em São Paulo. Revista Brasileira de História da Educação, n. 22, p. 17-41, jan./abr. 2010.

CHARTIER, Roger. O mundo como representação. Estudos Avançados. São Paulo, v. 5, n. 11, abril. 1991, p. 173-191.

CHARTIER, Roger. A história ou a leitura do tempo. Tradução Cristina Antunes. 2. ed. $3^{\text {a }}$ reimpressão. Belo Horizonte, MG: Autêntica Editora, 2017. LE GOFF, Jacques. História e Memória. Campinas, SP: Ed. da Unicamp, 1990. LIMA, Nestor dos Santos. Da organização do ensino normal, profissional e primário no sul do Brasil e no Rio da Prata. Natal: Typ. d'A República, 1923.

MENEZES, Antônio Basílio Novaes Thomaz de. A presença do higienismo na educação potiguar: a perspectiva educacional de Nestor dos Santos Lima (19211927). In: STAMATTO, Maria Inês Sucupira; NETA, Olívia Morais de Medeiros (Org.) Práticas educativas, formação e memória. Campinas, SP: Mercado de letras, 2015, p. $121-146$.

MIGNOT, Ana Chrystina Venancio. Viajar para legitimar: Armanda Álvaro Alberto na Comissão de Intercâmbio Brasil-Uruguai (1931). Revista Brasileira de História da Educação, n. 22. jan./abr. 2010, p. 43-64.

MIGNOT, Ana ChrystinaVenancio; GONDRA, José Gonçalves (Orgs.). Viagens Pedagógicas. São Paulo, Cortez, 2007.

PETROVICH, Enélio Lima. Nestor dos Santos Lima: aspectos de sua vida e obra. Revista do Instituto Histórico e Geográfico do Rio Grande do Norte. Natal, v. 79 e 8o, p. 76-81, 1987 e 1988.

REVISTA DO INSTITUTO HISTÓRICO E GEOGRÁFICO DO RIO GRANDE DO NORTE. Vols. XX. XXI. XXII. Natal. Tipografia da Imprensa Diocesana. 1923, 1924,1925 .

RIO GRANDE DO NORTE. Mensagem dos governadores. Natal: Typographia d'A República, 1923.

RIO GRANDE DO NORTE. Departamento de Educação do Estado. Álbum de Fotografias do Departamento de Educação (1927)

SILVA, Alexandra Lima da. Ideias em movimento: viagem como horizonte na historiografia da educação. Roteiro, Ed. Especial. Joaçaba, p. 109-126, 2013. Ed. 


\section{Especial}

SIRINELLI, Jean François. Os intelectuais. In: REMOND, René (Org.). Por uma história política. Rio de Janeiro: Fundação Getúlio Vargas, 2003, p. 231-269.

SOUZA, Itamar. Nestor dos Santos Lima, historiador. Natal. 1987. Conferência pronunciada em 10 de agosto de 1987 no Instituto Histórico e Geográfico do Rio Grande do Norte.

VIDAL, Diana.; SILVA, José Cláudio Sooma. Intérpretes do passado e do presente: a arte de historiadores da educação e arquivistas. History of Education in LatinAmerica - HistELA, v. 3, p. e20951, 19 maio 2020.

LAIS PAULA DE MEDEIROS CAMPOS AZEVEDO é doutoranda em Educação pelo Programa de Pós-graduação em Educação da Universidade Federal do Rio Grande do Norte (PPGED/UFRN) e mestre em Educação pela mesma instituição. Possui graduação em Pedagogia pela Faculdade de Ciências Cultura e Extensão do Rio Grande do Norte e graduação em Tecnologia em Lazer e Qualidade de Vida pelo Instituto Federal de Educação, Ciência e Tecnologia do Rio Grande do Norte. Tem experiência na área de Educação, com ênfase em História da Educação, atuando principalmente nos seguintes temas: história e historiografia da educação, história transnacional da educação e história intelectual.

E-mail: laispaulamedeiros@gmail.com

(1) http://orcid.org/0000-0003-3274-5798

OLÍVIA MORAIS DE MEDEIROS NETA possui doutorado em Educação, mestrado em História e graduação em História (Licenciatura e Bacharelado) pela Universidade Federal do Rio Grande do Norte. É professora do Centro de Educação da Universidade Federal do Rio Grande do Norte e atua como professora-orientadora no Programa de PósGraduação em Educação (UFRN) e no Programa de Pós-Graduação em Educação Profissional do Instituto Federal de Educação, Ciência e Tecnologia do Rio Grande do Norte (IFRN). É editora da Revista Brasileira de Educação Profissional e Tecnológica (ISSN 1983-0408) e History of Education in Latin America - HistELA (ISSN 2596-0113).

E-mail: olivianeta@gmail.com

(i) http://orcid.org/0000-0002-4217-2914 
Revista História da Educação (Online), 2021, v. 25: e108743 DOI: http://dx.doi.org/10.1590/2236-3459/108743
0-ISSN: 2236-3459 http://seer.ufrgs.br/asphe

Recebido em: 26 de outubro de 2020

Aprovado em: 06 de setembro de 2021

Editora responsável: Terciane Luchese

(C) (1)

Revista História da Educação - RHE

Associação Sul-Rio-Grandense de Pesquisadores em História da Educação - Asphe

Artigo de acesso aberto distribuído nos termos de licença Creative Commons. 